ROCZNIKI HUMANISTYCZNE

Tom LXVIII, zeszyt $10 \quad-\quad 2020$

DOI: http://dx.doi.org/10.18290/rh206810-6

\title{
ANNA PETRIKOVA
}

\section{РОЛЬ ПЕРЕВОДА В ОБУЧЕНИИ РУССКОМУ ЯЗЫКУ \\ КАК ИНОСТРАННОМУ СТУДЕНТОВ-РУСИСТОВ НА ПРИМЕРЕ ОПРОСА СЛОВАЦКИХ СТУДЕНТОВ ФИЛОСОФСКОГО ФАКУЛЬТЕТА ПРЕШОВСКОГО УНИВЕРСИТЕТА}

\section{ВВЕДЕНИЕ}

Великий гуманист и просветитель Ян Амос Коменский относится к педагогам средневековья, отстаивающим школьное обучение национальным языкам, формирование которых происходило на базе заимствования из иностранных языков, греческого и латинского, алфавита, словарного состава, грамматического строя и т.д. В труде «Великая дидактика» педагог упоминает перевод в качестве способа обучения стилистике. В рамках данного подхода обучаемые развивают не только способность автономной работы на уроке, находить ошибки в письменных работах соклассников, проверять орфографию, но и практиковать переводческие умения с одного языка на другой, а также заниматься критикой перевода: «Затем пусть будет предоставлена возможность критики того же перевода остальным ученикам из той же декурии, а далее всему классу; наконец, если будет нужно, пусть сделает указания

Доцент АннА ПЕтриковА, кандидат филологических наук - Прешовский университет, Словакия, преподаватель Института русистики Философского факультета; e-mail: anna. petrikova@unipo.sk. ORCID: https://orcid.org/0000-0003-0949-7167.

Dr AnNa Petrikova, profesor nadzw. - Uniwerytet w Preszowie, Słowacja, wykładowca w Instytucie Rusycystyki na Wydziale Filozoficznym; e-mail: anna.petrikova@unipo.sk. ORCID: https://orcid.org/ 0000-0003-0949-7167.

Anna Petrikova, PhD in Philology - University of Presov, Slovakia, Institute of Russian Studies at the Faculty of Philosophy; e-mail: anna.petrikova@unipo.sk. ORCID: https://orcid.org/ 0000-0003-0949-7167. 
учитель» (Komenskiy/Коменский 195). Пример свидетельствует об использовании перевода в качестве практической деятельности, которая стимулирует и вовлекает студентов в металингвистическую задачу, сосредотачивая внимание на особенностях структуры языка, повышая тем самым лингвистическую компетенцию, включающую в себя овладение фонематическими, орфографическими, лексическими, грамматическими средствами, что, по мнению Н. Хомского, является идеальным грамматическим знанием, соотносимым со знанием языковой системы. Именно «знание системы языка и правил оперирования языковыми средствами в процессе речевой деятельности» (Nelyubin/Нелюбин 110) в современной концепции обучения иностранным языкам является ядром лингвистической и «коммуникативной компетенции билингвов» (Szutkowski 95).

Среди методистов сложилось два мнения по поводу использования перевода в изучении иностранных языков: признание метода и отказ от него. В конце XVIII формируется новаторский грамматико-переводной метод, сторонники которого рекомендовали всем учащимся независимо от возраста, цели обучения и продолжительности курса. По словам А.В. Конышевой, метод был еще неразработанный, односторонний, «не учитывавший психологических особенностей учащихся» (9). Противоположный ему прямой метод, уделявший больше внимания речевой практике, пренебрегал переводом и грамматикой. Перевод как языковая деятельность считался неподходящим в контексте изучения иностранных языков.

Основным тезисом настоящего исследования является утверждение, что переводческая деятельность является средством повышения уровня владения иностранным языком, поскольку перевод является надежным методом языковой практики и совершенствования коммуникативной компетенции. В данной статье мы поставили две цели, во-первых - описание умения переводческой деятельности в аудитории, которое повышает знания студентов об использовании языка, и, во-вторых, вопрос полезности перевода в изучении родного языка. Из методов исследования мы используем обзор и анализ теоретического материала, анализ результатов опроса 38 студентов-русистов Философского факультета Прешовского университета. К сожалению, количество студентов, изучающих русский язык не только в Прешове, но и в других вузах Словакии невелико. Нас интересует прежде всего ситуация в тех группах студентов, в которых я непосредственно веду занятия. Таким образом, 
опрос не претендует на репрезентативность в рамках Словакии, но отражает мнение студентов, которые получают образование в Прешовском университете. Мы считаем, что результаты опроса важно осмыслить и в дальнейшем использовать перевод в процессе обучения.

\section{1. НАУЧНЫЕ ОСНОВАНИЯ ИСПОЛЬЗОВАНИЯ ПЕРЕВОДА В ОБУЧЕНИИ ИНОСТРАННОМУ ЯЗЫКУ}

Перевод всегда был ядром споров о том, может ли он действительно быть эффективным инструментом в изучении иностранного языка. Перевод часто рассматривался как механическая передача языкового значения с одного языка на другой (Brown). Даже сегодня он не воспринимается как полезный инструмент для изучения языка, поскольку не является коммуникативной деятельностью, которая должна соответствовать общим потребностям изучающего язык. Перевод считается трудоемким, скучным и неуместным.

К. Малмкяер (Malmkjaer 6) кратко обобщает основные причины, по которым перевод потерял на популярности:

1. Перевод независим и радикально отличается из четырех умений, которые определяют языковую компетентность: чтение, письмо, говорение и аудирование.

2. Перевод занимает драгоценное время, которое может быть использовано для обучения этим четырем умениям.

3. Перевод - это противоестественно.

4. Перевод вводит студентов в заблуждение и мешает им думать на иностранном языке.

5. Перевод - это плохой тест на знание языка.

6. Перевод создает помехи в восприятии языка, его декодировании.

7. Перевод подходит только для обучения переводчиков.

Однако, в последние несколько десятилетий зафиксирован растущий интерес к переводческой практике на уроках иностранного языка. Возможности использования перевода в процессе обучения не потеряли своей актуальности и широко используются.

Многие учителя иностранных языков возрождают использование перевода в разных учебных целях. Было отмечено, что переводческая деятельность может использоваться в педагогических целях наряду с другими традиционными языковыми учебными заданиями. Чтение, упраж- 
нения по грамматике, перевод воспринимаются учащимися как некое средство формирования «способности к обучению» (McDonough 409). Владение переводческими умениями свидетельствует о способности учащегося переносить уже сформированные навыки и умения на изучаемом языке на новый вид речевой деятельности, каковым является перевод.

К. Шаффнер (Schaffner) утверждает, что перевод и связанные с ним упражнения, могут быть полезны для студента, который изучает иностранный язык:

1. Улучшение речевой практики.

2. Расширение словарного запаса в Я2.

3. Понимание способа функционирования языка.

5. Консолидация структуры Я2 для активного использования.

6. Контроль и улучшение понимания Я2.

Целесообразность учебного перевода аргументировали в своих научных публикациях Э.Г. Азимов, Л.С. Бархударов, А.Н. Щукин, Г.И. Дергачёва, К. Malmkjaer, Э.Р. Михайлова, И.Б. Гецкина и многие другие. Так, О.В. Шеремет отмечает необходимость использования перевода «особенно на начальном этапе обучения иностранному языку: студенты сознательно или бессознательно стремятся к сравнению и сопоставлению лингвистических фактов в двух языках. [...]. Рациональное использование перевода в учебном процессе способствует комплексному формированию переводческих умений и навыков, необходимых будущим филологам для осуществления профессиональной деятельности» (Sheremet/Шеремет 102)

Русский ученый Б.В. Беляев определяет перевод как «деятельность человека, имеющую психологическую основу» (Belyayev/Беляев 149). Это значит, что не только виды речевой деятельности взаимосвязаны с мышлением на иностранном языке, но и перевод также, поскольку и при переводе необходимо передавать мысли средствами иностранного языка.

Умение переводить - это передача смысла информации с одного языка на другой, и это умение необходимо развивать так же, как и другие умения слушания, говорения, чтения, письменной речи. Это особый вид речевой деятельности (Belyayev/Беляев 151).

Б.В. Беляев выделяет несколько способов применения перевода в обучении: «как в качестве средства основного средства обучения, и, стало быть, овладения иностранным языком, так и в качестве одной из 
основных целей этого обучения. Дополнительно к этому нужно также различать использование перевода при сообщении учащимся теоретических сведений о языке (например, переводная семантизация иноязычных слов, перевод в целях сравнения иноязычных средств выражения какой-либо мысли со средствами родного языка и т.п.) и использование перевода при практической тренировке учащихся в иноязычной речи (например, в целях понимания читаемого или в целях контроля этого понимания» (Belyayev/Беляев 150).

Таким образом, мы можем понимать под учебным переводом использование родного языка учащихся в процессе обучения иностранному языку, т. е. средство взаимопонимания собеседников (используется для семантизации единиц языка, контроля за их усвоениями, пояснения некоторых трудных для понимания особенностей изучаемого языка) (Petríková, Kuprina \& Gallo/Петрикова, Куприна и Галло).

\section{2. УЧЕБНЫЙ ПЕРЕВОД КАК ПРИЕМ ОБУЧЕНИЯ}

Учебный перевод при обучении иностранному языку выступает как вспомагательный вид коммуникативной деятельности, в отличие от профессионального перевода, который является самостоятельным предметом обучения.

Используя перевод при обучении иностранному языку, необходимо помнить, что с точки зрения психологии второй язык неизбежно усваивается через призму первого, родного (Леонтьев), поэтому важно обдумать подбор русскоязычного языкового материала и способ его введения, а также использовать перевод в качестве приема учения и обучения.

Необходимо учитывать, что «переводческая деятельность не должна осуществляться изолированно, а следует ее включать в занятия» (Ророvic). Поэтому перевод может использоваться как средство введения, закрепления и активизации единиц языка в их парадигматических, синтагматических и других связях. Учебный перевод также эффективен и как средство формирования коммуникативной компетенции. Овладение иностранным языком так или иначе опосредуется через родной, словацкий язык обучаемого, поэтому происходит неосознанный перенос речевых навыков и умений с родного языка на изучаемый на основе смыслового сходства. Если же целенаправленно использовать перевод 
в учебном процессе, то это может оказаться эффективным методическим приемом, превращающим неосознанный перенос в перенос осознанный.

Р. Попович предлагает модель урока, на котором используется перевод. В данную модель входит предпереводческая деятельность, целью которой является интеграция навыков перевода и чтения. На данном этапе реализуются 3 шага.

Шаг 1: Учитель начинает обсуждение темы занятия. Далее из текста студенты извлекают ключевые слова в Я2. Учитель записывает слова, которые студенты не знают (но они появляются в тексте) в Я1. Шаг 2: Студенты читают текст и в парах или в небольших группах пытаются найти эквиваленты Я2 из слов, написанных на доске. Шаг 3: Все студенты сравнивают результаты.

Следующий пример касается также предпереводческий деятельности, цель которой состоит в интеграции вокабуляра и письменной речи с переводом.

Шаг 1: словарная практика.

a) Какие из перечисленных ниже глаголов могут быть использованы с существительным в значении неодушевленного предмета?

б) Попробуйте их связать со следующими словами: эта статья

выявить иеель, рассмотреть, изучить документ, указать, показать

описать отчет, представить, идентифицировать, разработать, поддерживать, представление

стресс, спорить, комментировать, состояние, поставить вопрос, подробно

смотрите, выдвигайте, исследуйте, разбирайтесь с

Шаг 2: Как бы вы перевели эти словосочетания на родной язык?

Далее следует переводческая деятельность, целью которой является повышение осведомленности о роли контекста и лексического запаса. На данном этапе предлагаются 3 шага:

Шаг 1: разделите текст на три части, A, В и С; Образуйте группы по три человека и дайте каждому из группы отдельную часть для перевода. Шаг 2: Студенты, которым была дана одна и та же часть текста, формируют новые группы из трех человек, в которых они сравнивают и обсуждают свои переводы. Они также пытаются договориться об окончательной версии. Шаг 3: Студенты возвращаются в свои первоначальные 
группы, собирают переведенный текст, обсуждают его и вносят необходимые изменения.

После двух пройденных этапов наступает последний этап: деятельность после перевода. Его цель состоит в повышении лингвистической компетенции при помощи перевода.

Шаг 1: студенты сравнивают и обсуждают свои версии и заполняют сравнительную таблицу

\begin{tabular}{|l|c|c|}
\hline хорошо & не очень хорошо & плохо \\
\hline
\end{tabular}

В качестве средства обучения языку учебный перевод на занятиях по практике языка выполняет следующие функции:

1. функиию семантизации (перевод дает возможность уточнить значения вводимых единиц языка, их смысловую дифференциацию, взаимоотношения со сходными единицами в родном языке учащихся, что предотвращает интерференцию родного языка);

2. функиию закрепления (перевод является эффективным тренировочным упражнением для автоматизации употребления языковых единиц в речи и выработки навыков ориентации при выборе языковых средств);

3. функцию контроля и самоконтроля (перевод позволяет проверить точность понимания и прочность усвоения пройденного материала).

В зависимости от того, в каком отношении находятся значения слова в двух языках, возможен перевод:

- одним словом или словосочетанием;

- путём толкования значения слова на родном /иностранном языке;

- с помощью привлечения средств наглядности.

В процессе обучения предлагаем несколько возможностей применения учебного перевода:

1. при объяснении трудных случаев использования речевых средств в общении. Они или отсутствуют в родном языке учащихся, или являются причиной межъязыковой интерференции. При этом подобные объяснения должны быть практичными. Распространённая ошибка начинающих преподавателей - обширное объяснение теории языка на родном языке учащихся вместо практического овладения данными языковыми явлениями; 
2. при организации тренировки учащихся в иноязычной речи;

3. при контроле понимания нового учебного материала;

4. при ознакомлении учащихся с особенностями учебного перевода как способа речевой деятельности;

5. научиться пользоваться двуязычными и специальными словарями и справочниками;

6. научиться выполнять перевод на русский язык с опорой на словари с соблюдением норм русского языка;

7. научиться выполнять перевод на родной язык (соблюдение стилистических особенностей и других норм словацкого языка).

Важным моментом в применении перевода в обучении являются критерии переводческой деятельности, которые сформулировали исследователи Р. Ноласко и Л. Артур:

1. Язык используется для определенной цели.

2. Переводческая деятельность создает желание общаться.

3. Переводческая деятельность побуждает студентов творчески подходить к учебной деятельности и предлагать свои идеи.

4. Студенты сосредоточены на том, что они говорят, а не на том, как они говорят.

5. Студенты работают самостоятельно, без помощи преподавателя.

6. Студенты сами решают, что сказать или написать.

Перевод как вид речевой деятельности имеет много преимуществ, но и минусов, а именно:

1. Как и другие способы семантизации, не является универсальным способом пояснения значения слова: при несовпадении объема выражаемого словом понятия перевод не исчерпывает всех возможных значений переводимого слова, и , таким образом, перевод не следует использовать в качестве основного средства обучения языку.

2. Частое применение перевода как способа семантизации при всех его достоинствах (экономия во времени, наглядность) тормозит формирование беспереводного владения языком (при практическом обучении языку главной целью занятий является беспереводное овладение языком) (Nolasco, Arthur). 


\section{3. АНАЛИЗ И РЕЗУЛЬТАТЫ ОПРОСА}

Для того, чтобы мы могли оценить преимущества переводческой деятельности на русском языке в словацкой аудитории, мы провели опрос (см. Приложение). Выборка состояла из 38 студентов второго курса Философского факультета Прешовского университета, которые получают образование по специальности «преподаватель академических предметов русский язык и литература в комбинации с другим предметом (географией, математикой, словацким языком, педагогикой, украинским языком и литературой, обществоведением, историей)», «русистика» и «устный и письменный перевод». Опросник состоял из закрытых и открытых вопросов. Закрытые вопросы были в основном с ответом $\partial а /$ нет и на выбор нескольких вариантов. На открытые вопросы студенты отвечали своими словами. На все вопросы были получены ответы. Все опросники были возвращены. Полученные данные были проанализированы.

Анализ результатов опроса (вопрос № 1) показал, что практически все студенты рассматривают перевод как полезный инструмент обучения $(95 \%), 3 \%$ из них сомневались в пользе перевода, $2 \%$ студентов считали, что перевод не может помочь в изучении языка. $100 \%$ опрошенных выразило свое мнение о влиянии перевода на обучение их русскому языку.

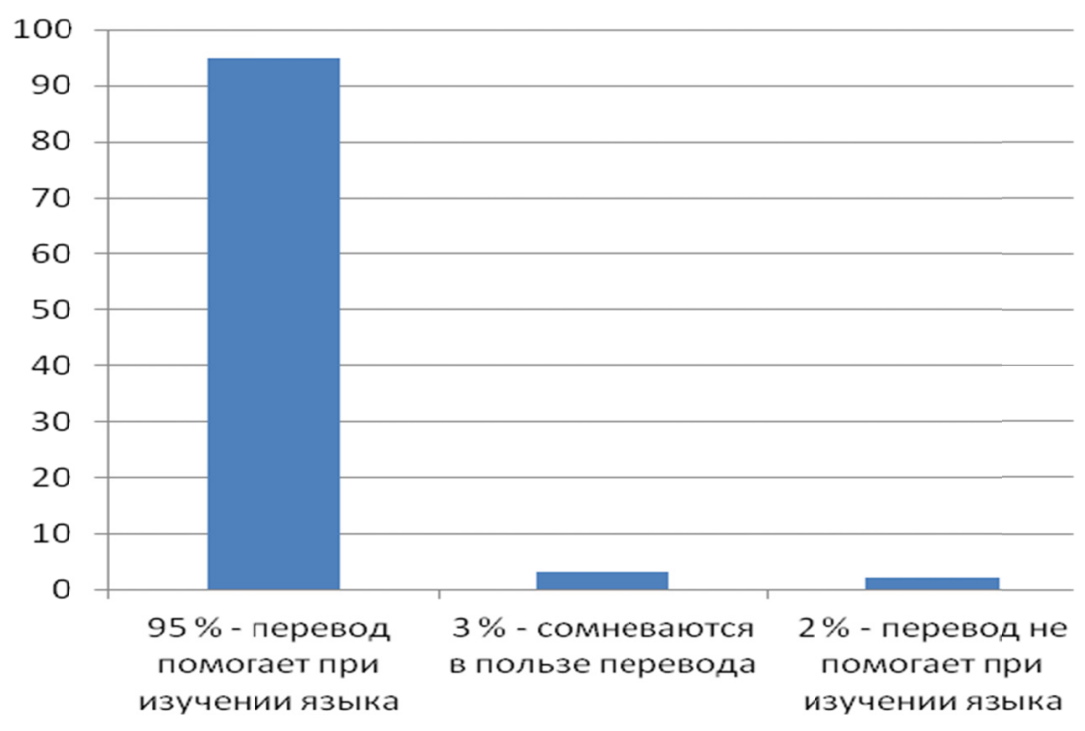

Диаграмма 1. Отношение студентов к переводческой деятельности. 
На вопрос № $2^{1}$ студенты отметили, что видят пользу в переводческой деятельности. Можно выделить следующие ответы студентов, например, студенты более активны, больше стараются и следят за преподавателем; увеличивается лексический запас; быстрее запоминаются новые слова; перевод помогает повысить языковой уровень; студент больше внимания уделяет учебе; улучшается процесс овладения русским языком; перевод отлично влияет на запоминание новых выражений; помогает в практике русской речи. Практически все ответы в большей или меньшей степени касаются словарного запаса: отдельных слов или словосочетаний. Один ответ отличается довольно выразительно, студентка отметила влияние перевода на развитие интеллектуальных способностей.

Результаты показывают, что студенты позитивно относятся к переводческой деятельности (вопрос № 3) и переводческие упражнения считают полезными в процессе обучения.

В вопросе № 4, достигнут ли быстрее лучших результатов в изучении языка, если будут использовать другие средства кроме перевода, $51 \%$ студентов ответили положительно, а 49 \% респондентов дали отрицательный ответ. Таким образом, больше половины студентов считают, что перевод является эффективным методом изучения языка.

Для вопроса № 5, с выраженной в нем просьбой выделить такие умения, на развитие которых перевод оказывает самое большое влияние, получены следующие ответы: $85 \%$ респондентов считают, что задания по переводу могут помочь улучшить грамматику, 35 \% предпочитают использовать переводческую деятельность для улучшения навыков письма и $40 \%$ связали перевод с совершенствованием речевых навыков. Только $20 \%$ из респондентов выразили желание использовать перевод для совершенствования навыков аудирования.

\footnotetext{
${ }^{1}$ В данном случае не приводим диаграмму, так как вопрос был открытый, формулировки менялись, но мы смогли выявить общую тенденцию среди опрашиваемых студентов.
} 


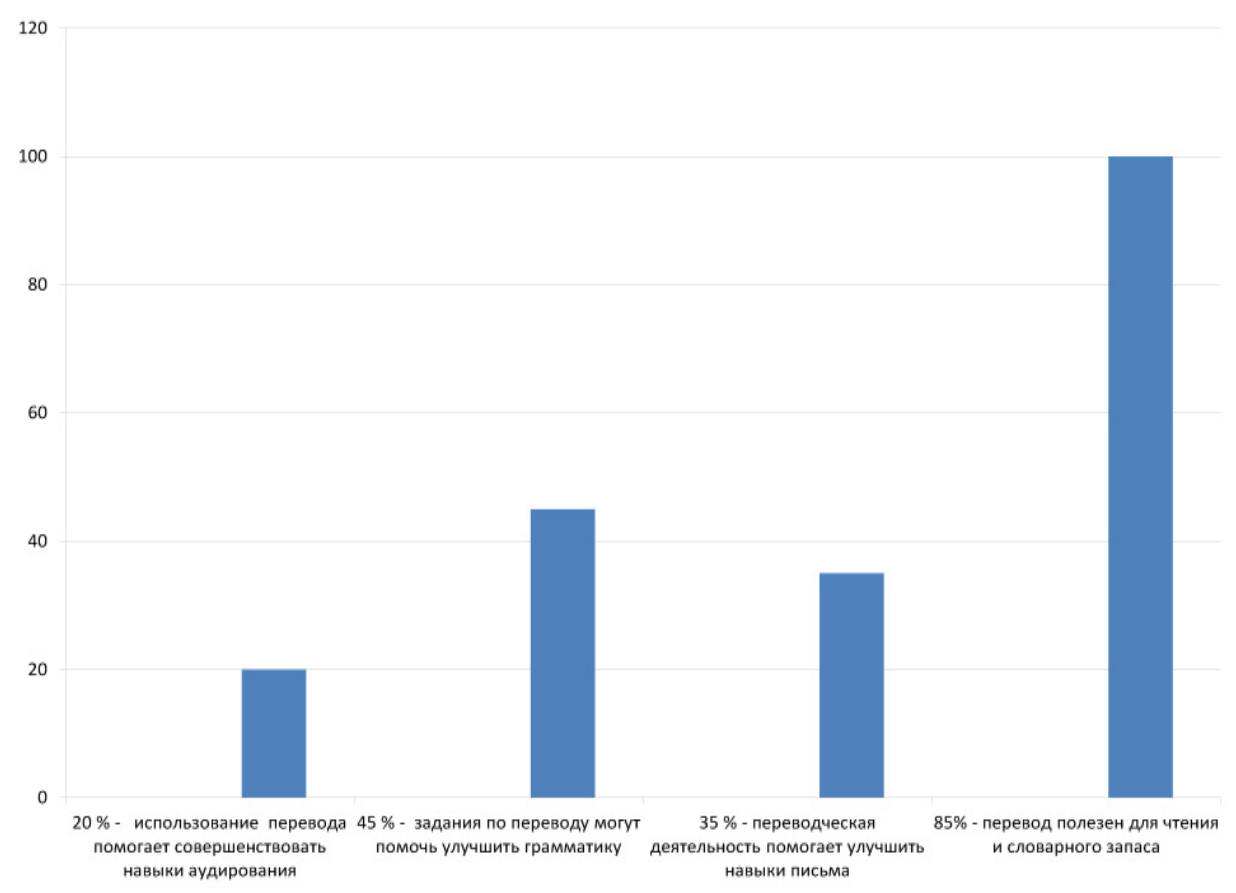

Диаграмма 2. Виды речевой деятельности и переводческая деятельность.

Вопрос № 6 (см. Приложение) касался использования переводческой деятельности на занятиях. 90 \% ответили положительно и только $10 \%$ дали отрицательный ответ. Студенты выделили следующие преимущества использования перевода на занятиях: понять словарный заnас, развитие вокабуляра, помогают в обучении; улучшается компетенция, подготовка студентов; развитие умения говорения и чтения; тренируется грамматика; легче будет изучаться язык $и$ др. Снова можно выделить один ответ, который отличается от остальных, речь идет о той же самой студентке, которая и при вопросе № 2 отметила роль интеллектуальных способностей.

Результаты опроса свидетельствуют о том, что перевод действительно является полезным инструментом в изучении иностранного языка. Большинство студентов считают, что перевод помогает приобретать знания, вырабатывать навыки говорения, аудирования, чтения, письменной речи, развивать лексические и грамматические средства межкультурного общения. 


\section{ВЫВОДЫ}

Настоящее исследование показывает, что переводческая деятельность является полезным педагогическим инструментом, а также средством улучшения видов речевых деятельности. Проведенный опрос показал, что, систематически внедряя перевод на занятиях, мы можем помочь студентам развивать и совершенствовать умения чтения, говорения, письма, расширять лексику и совершенствовать грамматику. Перевод на русский язык помогает словацким студентам лучше понимать структуру языка, а также улучшает навыки перевода. Конечно, этот эффективный инструмент обучения не стоит чрезмерно использовать, но тем не менее, перевод должен быть интегрирован в преподавание русского языка словацким студентам в нужное время и с конкретной целью обучения.

\section{БИБЛИОГРАФИЯ}

Atkinson, David. Teaching Monolingual Classes. Longman, 1993.

Belyayev, B[oris] V[asil'yevich]. Ocherki po psikhologii obucheniya inostrannym yazykam. 2-ye izd. Prosveshcheniye, 1965 [Беляев, Б[орис] В[асильевич]. Очерки по психологии обучения иностранным языкам. 2-е изд. Просвещение, 1965].

Brown, H. Douglas. Principles of Language Learning and Teaching. $4^{\text {th }}$ ed. Longman, 2002.

Dergachëva, G.I. Perevod kak odin iz aspektov obucheniya russkomu yazyku inostrannykh studentov-filologov. Russkiy yazyk, 1984 [Дергачёва, Г.И. Перевод как один из аспектов обучения русскому языку иностранных студентов-филологов. Русский язык, 1984].

Komenskiy, Yan Amos. Velikaya didaktika. Gosudarstvennoye Uchebno-pedagogicheskoye Izdatel'stvo Narkomprosa RSFSR [Коменский, Ян Амос. Великая дидактика. Государственное Учебно-педагогическое издательство Наркомпроса РСФСР, 1939].

Konysheva, A[ngelina] V[iktorovna]. Sovremennyye metody obucheniya angliyskomu yazyku. Izd. 2-ye, stereotip. TetraSistems, 2004 [Конышева, А[нгелина] В[икторовна]. Современные методы обучения английскому языку. Изд. 2-е, стереотип. ТетраСистемс, 2004].

Leont'yev, A[leksey] A[lekseyevich]. «Psikhologicheskiye osnovy obucheniya russkomu yazyku». Russkiy yazyk za rubezhom, № 4, 1974, ss. 4-11 [Леонтьев, А[лексей] А[лексеевич]. «Психологические основы обучения русскому языку». Русский язык за рубежом, № 4, 1974, сс. 4-11].

Malmkjaer, Kirsten. Translation and Language Teaching. St Jerome, 1998.

McDonough, Jo. «The Teacher as Language Learner: Worlds of Differences?». ELT Journal, vol. 56, no 4, 2002, ss. 404-411. doi: 10.1093/elt/56.4.404.

Mikhaylova, E.R, \& I.B. Getskina, «Perevod kak sredstvo obucheniya inostrannomu yazyku». Nauchnyy al'manakh. Pedagogicheskiye nauki, № 8 (10), 2015, ss. 587-589 [Михайлова, Э.Р., и И.Б. Гецкина. «Перевод как средство обучения иностранному языку». Науч- 
ный альманах. Педагогические науки, № 8, 2015, cс. 587-589]. Издательство Ukonf, http://ucom.ru/ doc/na.2015.08.587.pdf. Доступ 28.09.2020.

Nelyubin, L[yev] L['vovich]. Tolkovyy perevodovedcheskiy slovar'. 3-ye izd., pererab. Flinta: Nauka, 2003. [Нелюбин, Л[ев] Л[ьвович]. Толковый переводоведческий словарь. 3-е изд., перераб. Флинта: Наука, 2003].

Nolasco, Rob, i Lois Arthur. Large Classes. Phoenix ELT, 1995.

Petríková, Anna, Tamara Kuprina \& Ján Gallo. Didaktika ruštiny II - reč a jej rozvíjanie prostredníctvom základných rečových aktivit. Filozofická fakulta Prešovskej univerzity v Prešove, 2013.

Popovic, Radmila. «The place of translation in Language Teaching». Sue Leather Associates, https://www.sueleatherassociates.com/ wp-content/uploads /2018/01/Article_translation in languageteaching.pdf. Доступ 28.09.2020.

Schaffner, Christina. Qualification for Professional Translators: Translation in Language Teaching Versus Teaching Translation. St. Jerome publishing, 1998.

Sheremet, O.V. «Modernizatsiya uchebnogo perevodakak metodicheskogo priyema obucheniya russkomu yazyku v turetskoy auditorii», Yazyk i tekst - Language and Texr, tom 6, № 1, 2019, ss. 97-104. doi: 10.17759/langt.20190601171 [Шеремет, О.В. «Модернизация учебного перевода как методического приема обучения русскому языку в турецкой аудитории». Язык и текст - Language and Text, Том 6, № 1, 2019, сc. 97-104. doi: 10.17759/ langt.2019060117].

Štátny pedagogický ústav. Štátný vzdelávaci program. Ruský jazyk (Vzdelávacia oblast': Jazyk a komunikácia). Príloha ISCED 3 B 2.85 s., https:/www.statpedu.sk/ files/ articles/ dokumenty/statny-vzdelavaci-program/rusky_jazyk_isced1.pdf. Доступ 28.09.2020.

Szutkowski, Tomasz. «Subkompetencja frazeologiczna studentów-neofilologów jako składnik kompetencji językowej tłumacza - badanie pilotażowe», Roczniki Humanistyczne, Tom 67, z. 7, 2019, ss. 95-111. doi: 10.18290/rh.2019.67.7-6.

\section{РОЛЬ ПЕРЕВОДА В ОБУЧЕНИИ РУССКОМУ ЯЗЫКУ КАК ИНОСТРАННОМУ СТУДЕНТОВ-РУСИСТОВ НА ПРИМЕРЕ ОПРОСА СЛОВАЦКИХ СТУДЕНТОВ ФИЛОСОФСКОГО ФАКУЛЬТЕТА ПРЕШОВСКОГО УНИВЕРСИТЕТА}

Р е $з$ ю м е

В современных условиях образования повышается необходимость использования перевода в процессе обучения русского языка как иностранного. Использование перевода в истории преподавания иностранного языка имело много взлетов и падений. Считается, что перевод доминировал во время господства грамматико-переводного метода обучения, но с появлением прямого метода и других реформированных методов, перевод утрачивает свою ведущую позицию. Однако, в последнее время некоторые ученые призывают к возрождению использования перевода в обучении, поскольку перевод может облегчить процесс изучения языка. В данной статье приводится краткий обзор теоретической литературы, анализ результатов проведенного исследования в Прешовском университете. Результаты исследования свидетельствуют о том, что перевод является полезным инструментом в обучении русскому языку, направленным на совершенствование иноязычных навыков студентов.

Ключевые слова: перевод; обучение иностранному языку; студенты; интервью; лингвистическая компетентность. 


\title{
ROLA TŁUMACZENIA W NAUCZANIU \\ JĘZYKA ROSYJSKIEGO JAKO OBCEGO STUDENTÓW RUSYCYSTYKI NA PRZYKŁADZIE BADANIA STUDENTÓW SŁOWACKICH Z WYDZIAŁU FILOZOFICZNEGO UNIWERSYTETU W PRESZOWIE
}

\author{
Streszczenie
}

Stosowanie tłumaczenia w nauczaniu języków (ang. Translation in Language Teaching, TILT) miało wzloty i upadki w swojej historii. Chociaż dominowało w Grammar Translation Method (GTM), wraz z pojawieniem się Metody bezpośredniej i innych nurtów reformujących proces edukacji niektórzy uczeni nakłaniali do odrodzenia TILT, ponieważ wierzyli, że thumaczenie może ułatwić proces nauczania języka. W artykule zaprezentowano krótki przegląd literatury przedmiotu oraz wyniki ankiety, które sugerują, że tłumaczenie jest użytecznym narzędziem w nauce języka rosyjskiego, mającym na celu podniesienie kompetencji językowych studentów.

\section{Przektad streszczenia angielskiego}

Słowa kluczowe: tłumaczenie; nauczanie języków obcych; studenci; wywiad; kompetencje językowe.

\author{
THE ROLE OF TRANSLATION IN TEACHING RUSSIAN \\ AS FOREIGN LANGUAGE TO RUSSIAN STUDIES STUDENTS \\ BASED ON THE EXAMPLE OF A SURVEY OF SLOVAK STUDENTS \\ FROM THE FACULTY OF ARTS AT THE PREŠOV UNIVERSITY
}

\section{Su m m a r y}

The use of Translation in Language Teaching (TILT) has had many ups and downs over its history. While it was dominant during the Grammar Translation Method (GTM), by the advent of the "Direct Method" and "Reform Movement", however, some scholars were calling for the revival of TILT, as they believed that translation could facilitate the process of language learning. This paper is based on a brief overview of the theoretical literature and an analysis of the results of the survey. The findings of this survey suggest that translation is a useful tool in Russian-language learning, aimed at the enhancement of students' foreign language skills.

Key words: translation; foreign language teaching; students; interview; linguistic competence. 


\section{ПРИЛОЖЕНИЕ: ОПРОСНИК (НА СЛОВАЦКОМ ЯЗЫКЕ)}

\section{Pohlavie}

\section{Dotazník}

\section{Vek}

Odbor štúdia

\section{Kombinácia}

1. Nakol'ko je preklad ako prostriedok učenia sa ruštiny užitočný?
a) užitočný
b) neviem presne
c) nie je užitočný
d) neviem

2. Ako vplýva použivanie prekladu na štúdium ruštiny?

3. Máte radi cvičenia na preklad?
a) áno
b) nie

4. Myslíte si, že by ste mohli dosiahnut' lepší pokrok v štúdiu cudzích jazykov inými prostriedkami?
a) áno
b) nie

5. Aké jazykové zručnosti môžete najviac posilnit’ pomocou prekladu (viac možnosti)?
a) čítanie a slovná zásoba
b) gramatika
c) rozprávanie
d) písanie
e) počúvanie

6. Mali by sa prekladatel'ské aktivity používat' na hodinách cudzieho jazyka? Prečo áno/ prečo nie?
a) áno
b) nie 